\title{
Anthropometric and aesthetic analysis of the Indian American woman's face
}

\author{
Omar F. Husein*, Ali Sepehr, Rohit Garg, Mehdi Sina-Khadiv, Shilpa Gattu, \\ Joshua Waltzman, Edward C. Wu, Mason Shieh, Gregory M. Heitmann, \\ Samuel E. Galle
}

Division of Facial Plastic \& Reconstructive Surgery, The Department of Otolaryngology - Head \& Neck Surgery, UC Irvine Medical Center, Orange, CA, USA

Received 14 January 2009; accepted 28 October 2009

\author{
KEYWORDS \\ Facial anthropometrics; \\ Facial aesthetics; \\ Facial photogrammatic \\ analysis; \\ Transcultural \\ aesthetics; \\ Facial self-esteem
}

\begin{abstract}
Summary Background: This is the first study defining the facial anthropometric and aesthetic measurements in Indian American women (IAW).

Methods: This is a prospective cohort study involving evaluation of facial photographs. Frontal, lateral and basal photographs were taken of IAW $(n=102)$, and 30 anthropometric measurements were determined. Proportions were compared with published North American white women (NAWW) norms. Judges $(n=6)$ evaluated the photographs for aesthetics using a visual analogue scale. Attractive IAW (top 15\%) were compared with average IAW (remaining 85\%) and average NAWW. All completed a facial self-esteem survey.

Results: There were significant differences between IAW and NAWW in 25 of 30 facial measurements. Six measurements correlated with aesthetic scores: intercanthal distance, mouth width, nasolabial angle, midface height 2, ear length and nasal height. Attractive IAW had nine measurements approximating NAWW features, 15 measurements similar to average IAW values and two measurements distinct from both average IAW and average NAWW. Attractive IAW had higher facial self-esteem scores than average IAW.

Conclusions: Facial measurements in IAW are much different from NAWW, and these results will assist in preoperative planning. Several features are correlated with attractiveness in IAW: larger and wider-set eyes, a smaller midface, a smaller nose with greater tip rotation, smaller ears and a larger mouth. Attractive IAW display many measurements typical of average IAW and several measurements that reflect average NAWW values. These results contribute to
\end{abstract}

\footnotetext{
All authors have complied with the instructions and do accept the conditions posed by JPRAS. They have seen and agreed to the submitted version of the paper and bear responsibility for it. All contributors declare that this material is original and has been neither published elsewhere nor submitted for publication simultaneously. If accepted, the paper will not be published elsewhere in the same or similar form, in English or in any other language, without written consent of the copyright holder. There are no conflicts of interest, and there has not been any funding for this study.

* Corresponding author: Tel.: +1 5094749450.

E-mail address: tiffhusein@yahoo.com (O.F. Husein).
}

1748-6815/\$ - see front matter @ 2009 British Association of Plastic, Reconstructive and Aesthetic Surgeons. Published by Elsevier Ltd. All rights reserved. doi:10.1016/j.bjps.2009.10.032 
concepts of transcultural aesthetics - for a minority ethnic group, facial beauty appears to be an assimilation of deep-rooted ethnic features with prevailing cultural traits and aesthetic standards.

(C) 2009 British Association of Plastic, Reconstructive and Aesthetic Surgeons. Published by Elsevier Ltd. All rights reserved.

Anthropologists and clinicians have attempted for centuries to objectively comprehend the subjective concept of facial beauty. Renaissance artists emphasised that facial beauty is rooted in symmetric and balanced proportions. ${ }^{1}$ Their quantitative descriptions persisted as neoclassical canons, which are used in reconstructive facial analysis today. ${ }^{1}$ Much of the modern facial anthropometric data comes from Farkas' work on North American white populations. ${ }^{2,3}$ Recent studies on African Americans, Hispanics, Chinese and Koreans have demonstrated facial proportions very distinct from these studies. ${ }^{4-7}$

Asian Indians are the second-fastest growing ethnic group in the United States. ${ }^{8}$ This study aimed to establish the facial anthropometric data in Indian American women (IAW) and compare with the data available for North American white women (NAWW). The null hypothesis was that there would not be any significant differences in facial measurements between IAW and NAWW. While some aspects of facial beauty are universal, other standards vary from culture to culture. ${ }^{9}$ One phenomenon is that average measurements and proportions represent beauty more than extreme values. ${ }^{10}$ But what happens when an ethnic minority lives in a society dominated with aesthetic standards of the ethnic majority? Will beauty be the 'averageness' of the minority or the 'averageness' of the majority group, or will it be a complex combination of the two?

In a study comparing Korean American women to NAWW, 24 of 26 facial measurements were significantly different. ${ }^{7}$ Korean women judged to be attractive only had 9 of 26 measurements different than NAWW. ${ }^{7}$ The more the Korean women looked like the average NAWW, the more beautiful they were perceived to be. ${ }^{7}$ This suggests that the aesthetic standards of a predominant culture contribute to what is considered beautiful for other ethnic groups. This study sought to determine if IAW judged to be attractive demonstrated measurements similar to NAWW. The null hypothesis was that attractive IAW would not generate anthropometric data significantly different than average IAW or NAWW norms.

\section{Methods}

This was a prospective cohort study of 102 IAW. Participants were aged 18-30 years with both parents of Indian descent. Subjects were excluded if they had a history of facial trauma or surgery. Digital photographs (Nikon 8700, Nikon Corp, Tokyo, Japan) were acquired in frontal, lateral and basal views. A metric ruler was included in each image for calibration of measurements. All subjects filled out a self-esteem survey. For each of 32 facial features, a score from 1 to 5 indicated the degree of like or dislike.

Photographs were studied using Adobe Photoshop CS2 software (Adobe Systems, San Jose, CA, USA), and facial landmarks were identified (Figure 1). Subsequently, 30 anthropometric measurements were acquired. The results were compared with the data published for NAWW using an unpaired $t$ test with the Welch correction. Next, five neoclassical canons were used to investigate how well the two groups fit each analysis. ${ }^{2,11}$ Proportional differences

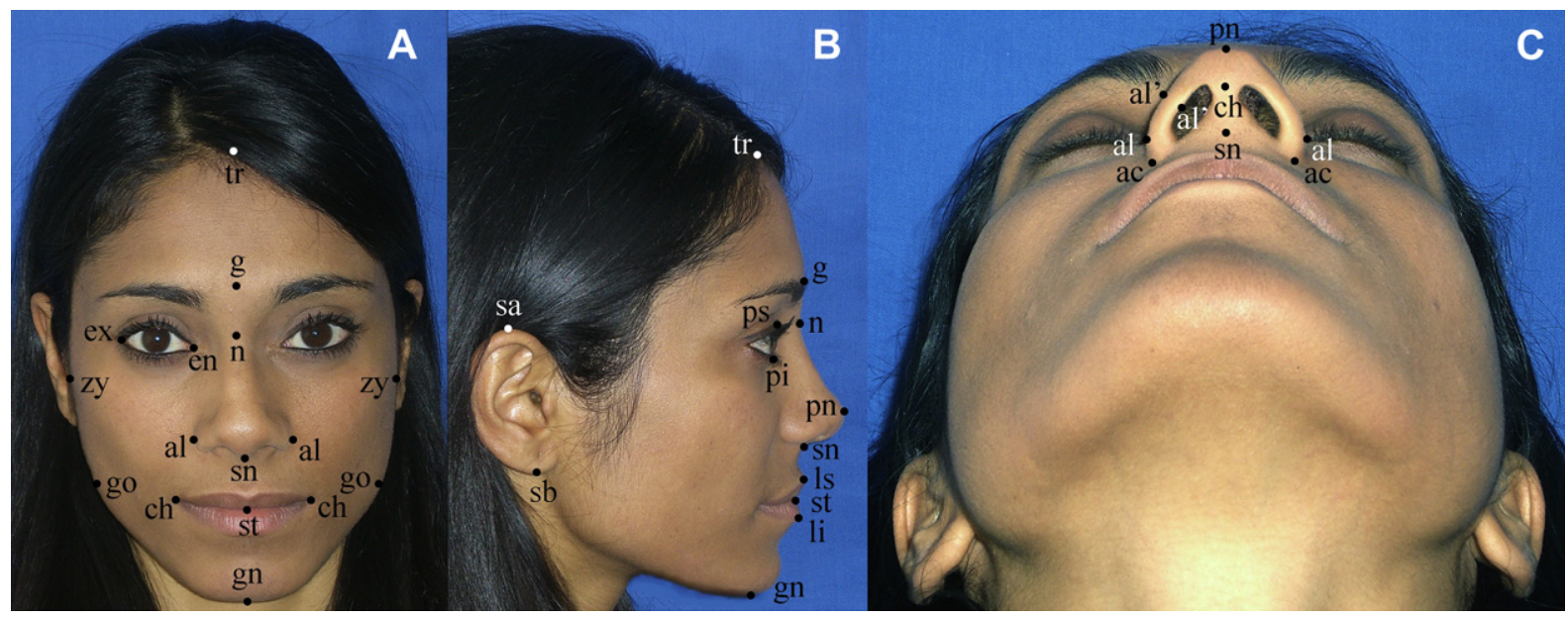

Figure 1 Facial soft tissue landmarks demonstrated on frontal (A), lateral (B), and basal (C) views. Abbreviations: ac, alar crease point; al, alare; al', alar rim; c, columella point; ch, cheilion; en, endocanthion; ex, exocanthion; g, glabella; gn, gnathion; go, gonion; li, labrale inferioris; ls, labrale superioris; $n$, nasion; pi, palpebrae inferioris; ps, palpebrae superioris; pn, pronasale; sa, superaurale; sb, subaurale; sn, subnasale; st, stomion; tr, trichion; zy, zygion. 
Table 1 Comparison of Anthropometric Facial Measurements in Indian American and North American White Women

\begin{tabular}{|c|c|c|c|c|}
\hline \multirow[t]{2}{*}{ Anthropometric Measure } & \multicolumn{4}{|l|}{ Mean (SD) Size } \\
\hline & Indian American $(\mathrm{n}=102)$ & North American White $(\mathrm{n}=200)$ & Mean Difference & $P$ Value \\
\hline total face height (tr-gn) & $169.4(13.3)$ & $172.5(7.5)$ & -3.1 & ${ }^{\mathrm{a}} 0.031$ \\
\hline morphological face height (n-gn) & $102.3(8.7)$ & $111.8(5.2)$ & -9.5 & ${ }^{a}<0.001$ \\
\hline forehead height 1 (tr-g) & $54.2(6.3)$ & $52.7(6.0)$ & 1.5 & ${ }^{\mathrm{a}} 0.048$ \\
\hline forehead height 2 (tr-n) & $63.9(7.4)$ & $63.0(6.0)$ & 0.9 & 0.289 \\
\hline midface height 1 (g-sn) & $58.1(5.5)$ & $63.1(4.4)$ & -5.0 & ${ }^{a}<0.001$ \\
\hline midface height 2 (n-st) & $65.0(4.2)$ & $69.4(3.2)$ & -4.4 & ${ }^{a}<0.001$ \\
\hline lower face height (sn-gn) & $57.8(7.5)$ & $64.3(4.0)$ & -6.5 & ${ }^{a}<0.001$ \\
\hline midface width (zy-zy) & $125.9(10.1)$ & $130.0(4.6)$ & -4.1 & $\mathrm{a}<0.001$ \\
\hline mandible width (go-go) & $95.2(11.0)$ & $91.1(5.9)$ & 4.1 & ${ }^{a}<0.001$ \\
\hline intercanthal width (en-en) & $31.2(3.7)$ & $31.8(2.3)$ & -0.6 & 0.137 \\
\hline eye fissure width (ex-en) & $30.6(2.4)$ & $30.7(1.2)$ & -0.1 & 0.693 \\
\hline eye fissure height (ps-pi) & $9.2(1.9)$ & $10.9(1.2)$ & -1.7 & $a^{a}<0.001$ \\
\hline 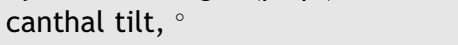 & $3.5(2.2)$ & $4.1(2.2)$ & -0.6 & ${ }^{\mathrm{a}} 0.026$ \\
\hline ear length (sa-sb) & $58.6(6.9)$ & $59.6(3.4)$ & -1.0 & 0.170 \\
\hline ear incline angle, ${ }^{\circ}$ & $12.3(4.7)$ & $17.5(4.6)$ & -5.2 & ${ }^{a}<0.001$ \\
\hline nasal height (n-sn) & $45.6(3.5)$ & $50.6(3.1)$ & -5.0 & $\mathrm{a}<0.001$ \\
\hline nasal length (n-pn) & 39.2 (3.9) & $44.7(3.4)$ & -5.5 & ${ }^{a}<0.001$ \\
\hline tip protrusion (sn-pn) & $19.1(2.0)$ & $19.7(1.6)$ & -0.6 & ${ }^{a} 0.009$ \\
\hline columella length (c-sn) & $9.1(1.9)$ & $11.5(1.7)$ & -2.4 & ${ }^{a}<0.001$ \\
\hline alar length (ac-pn) & $29.2(3.0)$ & $31.5(1.8)$ & -2.3 & $a^{a}<0.001$ \\
\hline alar thickness (al'-al') & $5.0(0.9)$ & $5.3(0.7)$ & -0.3 & ${ }^{\mathrm{a}} 0.004$ \\
\hline nasal width (al-al) & $35.6(3.3)$ & $31.4(2.0)$ & 4.2 & ${ }^{a}<0.001$ \\
\hline nasal base width (ac-ac) & $31.9(5.1)$ & $30.5(2.2)$ & 1.4 & ${ }^{\mathrm{a}} 0.009$ \\
\hline mouth width (ch-ch) & $51.1(5.2)$ & $50.2(3.5)$ & 0.9 & 0.117 \\
\hline upper lip height (sn-st) & $18.6(3.2)$ & $20.1(2.0)$ & -1.5 & ${ }^{a}<0.001$ \\
\hline upper lip thickness (ls-st) & $8.3(1.0)$ & $8.7(1.3)$ & -0.4 & a 0.003 \\
\hline lower lip thickness (li-st) & $10.1(1.3)$ & $9.4(1.5)$ & 0.7 & ${ }^{a}<0.001$ \\
\hline nasofrontal angle, ${ }^{\circ}$ & $138.2(8.1)$ & $134.3(7.0)$ & 3.9 & ${ }^{a}<0.001$ \\
\hline nasofacial angle, ${ }^{\circ}$ & $31.8(4.5)$ & 29.9 (3.9) & 1.9 & ${ }^{a}<0.001$ \\
\hline nasolabial angle, $^{\circ}$ & $97.2(10.6)$ & $104.2(9.8)$ & -7.0 & ${ }^{a}<0.001$ \\
\hline
\end{tabular}

Abbreviations: ac, alar crease point; al, alare; al', alar rim; c, columella point; ch, cheilion; en, endocanthion; ex, exocanthion; g, glabella; gn, gnathion; go, gonion; li, labrale inferioris; ls, labrale superioris; $n$, nasion; pi, palpebrae inferioris; ps, palpebrae superioris; pn, pronasale; sa, superaurale; sb, subaurale; sn, subnasale; st, stomion; tr, trichion; zy, zygion. Unless otherwise noted, data are in millimeters.

$P$ Values based on unpaired t test with the Welch correction.

a Statistically significant difference.

between IAW and NAWW were determined using the twotailed Fisher's exact test. Indian American judges (three men and three women) evaluated subjects for aesthetics using a visual analogue scale from 1 to 10 . Measurements for the most attractive 15\% of IAW, the remaining (average) IAW and NAWW were quantitatively compared.

\section{Results}

Anthropometric facial measurements for IAW and norms for NAWW were compared (Table 1). Significant differences were found in 25 of 30 measurements. With respect to the five canons, all facial proportions were statistically different between IAW and NAWW (Table 2). In the aesthetic analysis, the mean score for all subjects was 5.5 (range: 1-10). Bivariate analysis revealed six measurements that correlated with higher aesthetic scores: shorter midface height 2, larger intercanthal distance, shorter ear length, shorter nasal height, larger mouth width and a larger nasolabial angle. Comparison showed four significant differences in the attractive group: shorter midface height 2, shorter nasal height, shorter nasal length and shorter ear length (Figure 2).

When average IAW were analysed with NAWW, 26 of 30 measurements were statistically different. In comparing attractive IAW with NAWW, 17 of the 30 measurements were different (Table 3). Of the 17 differences, 15 of these had also been different when comparing all IAW with NAWW. Once separated from average IAW, analysis of attractive IAW revealed two measurements that became significantly different from NAWW: ear lengths and mouth widths. The average IAW group had a mean self-esteem score of 3.4 while the attractive group gave a mean score of $3.7(p=0.039)$ (Table 4$)$. The most common self-liked feature was 'eyes', and the most disliked feature was 'nose'. When asked to report willingness to seek surgery to correct the feature most disliked, 32\% stated affirmatively. 
Table 2 Neoclassical Facial Canon Measurements in Indian American and North American White Women

\begin{tabular}{|c|c|c|c|}
\hline Neoclassical Canon & $\begin{array}{l}\text { Indian } \\
\text { American } \\
(\mathrm{n}=102)\end{array}$ & $\begin{array}{l}\text { North American } \\
\text { White }(n=102)\end{array}$ & $P$ value \\
\hline $\begin{array}{l}\text { Orbitonasal } \\
\text { en-en }<\text { al-al }\end{array}$ & $88(86)$ & $39(38)$ & \\
\hline $\begin{array}{l}\text { en-en }=\text { al-al } \\
\text { en-en }>\text { al-al }\end{array}$ & $\begin{array}{l}9(9) \\
5(5)\end{array}$ & $\begin{array}{l}42(41) \\
22(21)\end{array}$ & ${ }^{a}<0.00$ \\
\hline $\begin{array}{l}\text { Orbital } \\
\text { en-en }<\text { ex-en } \\
\text { en-en }=\text { ex-en } \\
\text { en-en }>\text { ex-en }\end{array}$ & $\begin{array}{l}33(32) \\
21(21) \\
48(47)\end{array}$ & $\begin{array}{l}16(16) \\
34(33) \\
53(52)\end{array}$ & ${ }^{\mathrm{a}} 0.024$ \\
\hline $\begin{array}{l}\text { Naso-oral } \\
\text { ch-ch }<1.5 \times(\text { al-al }) \\
\text { ch-ch }=1.5 \times(\text { al-al }) \\
\text { ch-ch }>1.5 \times(\text { al-al })\end{array}$ & $\begin{array}{l}62(61) \\
23(22) \\
17(17)\end{array}$ & $\begin{array}{l}20(19) \\
21(20) \\
62(60)\end{array}$ & ${ }^{\mathrm{a}}<0.001$ \\
\hline $\begin{array}{l}\text { Nasofacial } \\
\text { al-al }<0.25 \times(z y-z y) \\
\text { al-al }=0.25 \times(z y-z y) \\
\text { al-al }>0.25 \times(z y-z y)\end{array}$ & $\begin{array}{l}0 \\
6(6) \\
96(94)\end{array}$ & $\begin{array}{l}40(39) \\
38(37) \\
25(24)\end{array}$ & $\mathrm{a}<0.001$ \\
\hline $\begin{array}{l}\text { Horizontal thirds } \\
\text { tr-g }>\text { sn-gn }\end{array}$ & $27(26)$ & 0 & \\
\hline $\begin{array}{l}\operatorname{tr}-\mathrm{g}=\mathrm{sn}-\mathrm{gn} \\
\operatorname{tr}-\mathrm{g}<\mathrm{sn}-\mathrm{gn} \\
\mathrm{g}-\mathrm{sn}>\mathrm{sn}-\mathrm{gn}\end{array}$ & $\begin{array}{l}15(15) \\
60(59) \\
52(51)\end{array}$ & $\begin{array}{l}0 \\
103(100) \\
33(32)\end{array}$ & ${ }^{\mathrm{a}}<0.001$ \\
\hline $\mathrm{g}-\mathrm{sn}=\mathrm{sn}-\mathrm{gn}$ & 12 (12) & 0 & ${ }^{\mathrm{a}}<0.001$ \\
\hline $\begin{array}{l}\text { g-sn }<\text { sn-gn } \\
\text { g-sn }>\text { tr-g }\end{array}$ & $\begin{array}{l}38(37) \\
68(67)\end{array}$ & $\begin{array}{l}70(68) \\
95(93)\end{array}$ & \\
\hline $\begin{array}{l}\text { g-sn }=\text { tr-g } \\
\text { g-sn }<\text { tr-g }\end{array}$ & $\begin{array}{l}12(12) \\
22(21)\end{array}$ & $8(8)$ & ${ }^{\mathrm{a}} 0.002$ \\
\hline $\begin{array}{l}\text { Actual \% of total } \\
\text { vertical height }\end{array}$ & & & \\
\hline Upper third & 32 & 29 & \\
\hline Middle third & 34 & 35 & \\
\hline Lower third & 34 & 36 & \\
\hline
\end{tabular}

Abbreviations: al, alare; ch, cheillion; en, endocanthion; ex, exocanthion; g, glabella; gn, gnathion; sn, subnasale; tr, trichion; zy, zygion. Unless otherwise noted, data are number (percentage) of subjects.

$P$ values based on 2-tailed Fisher exact test.

a Statistically significant difference.

\section{Discussion}

The concept of facial attractiveness is a complex assimilation of innate perceptions and cultural stereotypes. ${ }^{12}$ In multiple cultures, young children gaze longer at attractive faces, suggesting that some perceptions of attractiveness are genetic in origin and are cross-cultural. ${ }^{13}$ Darwin noted that responses to facial expressions are instinctive, as he wrote that grief is interpreted by 'Europeans in exactly the same way as... the Aboriginal hill tribes of India. ${ }^{14}$ Others have discovered the principle of 'averageness in beauty', in that attractive faces will be symmetric and closer to the mean of the population. ${ }^{10}$

One goal was to elucidate mean standards of facial anthropometrics for a growing ethnic group that had yet to be studied - IAW. When compared with established data for NAWW, several differences were revealed. ${ }^{2,3}$ IAW had a larger forehead, a smaller midface, a smaller lower face, a shorter vertical face height, a narrower midface and a wider lower face. IAW faces demonstrated a wider nasofrontal angle, a wider nasofacial angle and a more acute nasolabial angle. The average IAW face also had smaller eyes and less-inclined ears. The upper lip was shorter and thinner while the lower lip was thicker. The IAW nose overall was smaller but wider. The null hypothesis was rejected, as the majority of facial anthropometric measurements were significantly different between IAW and NAWW.

The neoclassical canons of facial proportions were devised during the Renaissance era and are still used to guide surgeons today. ${ }^{6,11}$ In this study, 9\% of IAW validated the orbitonasal canon, which states that the nasal width equals the intercanthal distance. The vast majority $(86 \%)$ had a nose that was wider than the interorbital measurement. Similarly, $22 \%$ of IAW validated the naso-oral canon and only $6 \%$ validated the nasofacial canon. In these analyses, it was most common for the nose to be wider than recommended for the mouth and midface. However, most IAW have noses that are wider than other facial measurements - this is not a disproportion, and so these canons are determined to be invalid for IAW.

The orbital canon purports that the width of the eye should be equivalent to the intercanthal distance, and this was valid in $21 \%$. For some IAW the measurements will be equal, for some the eye will be larger (32\%) and for some the interorbital distance will be larger (47\%). IAW had a better fit to the canon of horizontal thirds than NAWW. For average IAW, the length of the midface (34\%) was nearly equivalent to the length of the lower face (34\%) and the length of the upper third (32\%) was slightly shorter - an almost perfect $1 / 3-1 / 3-1 / 3$ proportion. By comparison, the NAWW face demonstrated a lower third that was the longest (36\%) with a slightly shorter middle third (35\%) and a much shorter upper third (29\%). For all five neoclassical canons, the null hypothesis was rejected, as IAW demonstrated facial proportions distinct from NAWW.

The aesthetic analysis revealed that judges preferred IAW who had larger and wider-set eyes, a larger mouth, a smaller midface, smaller ears and a smaller nose with greater tip rotation. Average IAW were significantly different than NAWW in 26 of 30 measurements. However, attractive IAW differed from NAWW norms in 17 of 30 measurements. One initial hypothesis was that since the subjects and judges lived in North America, IAW would be perceived as attractive if they demonstrated facial attributes of the dominant ethnic group. In this study, this hypothesis was true for many but not all measurements. Compared with average IAW, attractive IAW approximated NAWW norms in nine measurements (Table 3). There were two measurements that were not significant differences when comparing average IAW to NAWW but became significant when comparing attractive IAW to NAWW: ear length and mouth width. Attractive IAW had smaller ears and wider mouths, and these measurements moved away from the white norms. From these results, it is appreciated that transcultural aesthetics involve an intertwining of minority ethnic features with majority ethnic traits. The null hypothesis was rejected, as attractive IAW demonstrated 

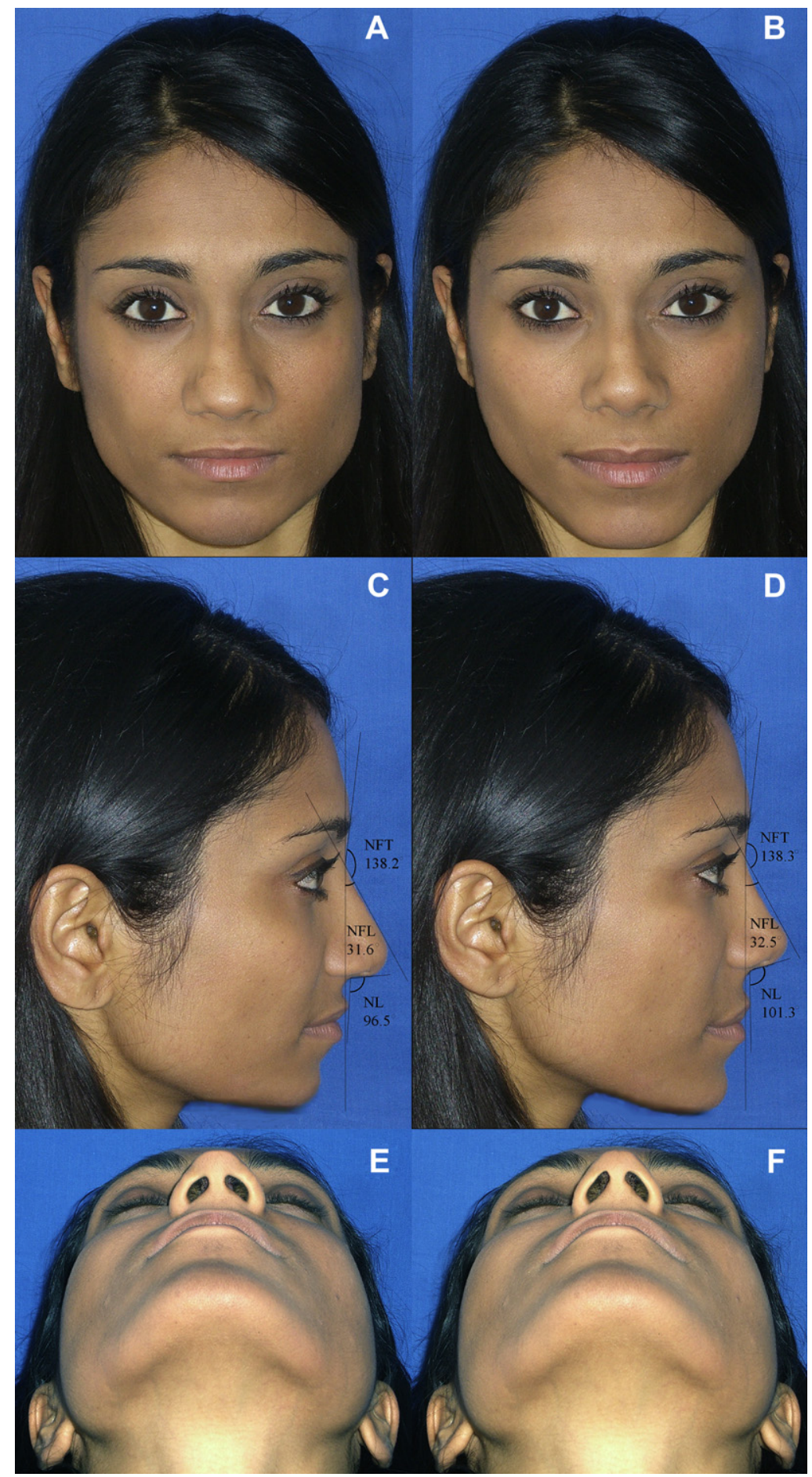

Figure 2 The same subject was computer morphed using measurements obtained for the average group (A, C, \& E) and measurements obtained for the attractive group ( $B, D, \&$ F). Note the following in the attractive face compared to the average face: wider eyes, larger intercanthal distance, greater canthal tilt, wider midface, smaller ears, smaller nose, less nasal tip projection but longer columella, larger nasolabial angle, wider mouth, longer upper lip, and longer lower third of the face. Only some of these were statistically significant differences (see text). Abbreviations: NFT, nasofrontal; NFL, nasofacial; NL, nasolabial.

anthropometric measurements that were different from both average IAW and average NAWW.

In this study, women judged to be attractive reported higher self-esteem scores than the other women. Several other studies have demonstrated this phenomenon - attractive individuals usually perceive that others think they are attractive and consider themselves to be attractive (higher self-esteem). ${ }^{15}$ The eyes were the feature most self-liked in this study. This correlates with the perception that Indian women are often 'known' for their beautiful 
Table 3 Comparison of Anthropometric Facial Measurements in Attractive and Average Indian American Women to North American White Women

\begin{tabular}{|c|c|c|c|c|c|c|c|}
\hline Anthropometric Measure & $\begin{array}{l}\text { North American } \\
\text { White Women } \\
(n=200)\end{array}$ & $\begin{array}{l}\text { Attractive Indian } \\
\text { American } \\
\text { Women }(n=16)\end{array}$ & $\begin{array}{l}\text { Mean } \\
\text { Difference }\end{array}$ & $P$ Value & $\begin{array}{l}\text { Average Indian } \\
\text { American } \\
\text { Women }(n=86)\end{array}$ & $\begin{array}{l}\text { Mean } \\
\text { Difference }\end{array}$ & $P$ Value \\
\hline total face height (tr-gn) & $172.5(7.5)$ & $169.9(13.3)$ & -2.6 & 0.439 & $169.3(13.4)$ & -3.2 & ${ }^{\mathrm{a}} 0.040$ \\
\hline $\begin{array}{l}\text { morphological face } \\
\text { height (n-gn) }\end{array}$ & $111.8(5.2)$ & $103.6(9.5)$ & -8.2 & ${ }^{\mathrm{a}} 0.004$ & $102.1(8.5)$ & -9.7 & ${ }^{a}<0.001$ \\
\hline forehead height 1 (tr-g) & $52.7(6.0)$ & $53.5(5.1)$ & 0.8 & 0.559 & $54.3(6.5)$ & 1.6 & ${ }^{\mathrm{a}} 0.045$ \\
\hline forehead height 2 (tr-n) & $63.0(6.0)$ & $63.4(6.5)$ & 0.4 & 0.815 & $64(7.6)$ & 1.0 & 0.281 \\
\hline midface height 1 (g-sn) & $63.1(4.4)$ & $58.7(6.6)$ & -4.4 & a 0.019 & $57.9(5.2)$ & -5.2 & $\mathrm{a}<0.001$ \\
\hline midface height 2 (n-st) & $69.4(3.2)$ & $63.1(3.4)$ & -6.3 & ${ }^{\mathrm{a}}<0.001$ & $65.4(4.2)$ & -4.0 & ${ }^{a}<0.001$ \\
\hline lower face height (sn-gn) & $64.3(4.0)$ & $60.0(8.9)$ & -4.3 & 0.075 & $57.4(7.1)$ & -6.9 & ${ }^{a}<0.001$ \\
\hline midface width (zy-zy) & $130.0(4.6)$ & $128.4(7.4)$ & -1.6 & 0.408 & $125.5(10.4)$ & -4.5 & ${ }^{a}<0.001$ \\
\hline mandible width (go-go) & $91.1(5.9)$ & $95.2(11.1)$ & 4.1 & ${ }^{\mathrm{a}} 0.015$ & $94.5(10.3)$ & 3.4 & ${ }^{\mathrm{a}} 0.005$ \\
\hline intercanthal width (en-en) & $31.8(2.3)$ & $32.5(3.5)$ & 0.7 & 0.443 & $31.0(3.7)$ & -0.8 & ${ }^{\mathrm{a}} 0.027$ \\
\hline eye fissure width (ex-en) & $30.7(1.2)$ & $31.4(1.8)$ & 0.7 & 0.146 & $30.4(2.5)$ & -0.3 & 0.291 \\
\hline eye fissure height (ps-pi) & $10.9(1.2)$ & $8.9(1.6)$ & -2.0 & ${ }^{a}<0.001$ & $9.1(1.8)$ & -1.8 & ${ }^{a}<0.001$ \\
\hline canthal tilt, ${ }^{\circ}$ & $4.1(2.2)$ & $4.1(2.7)$ & 0.0 & 1.000 & $3.4(2.7)$ & -0.7 & ${ }^{\mathrm{a}} 0.036$ \\
\hline ear length (sa-sb) & $59.6(3.4)$ & $54.5(3.6)$ & -5.1 & ${ }^{a}<0.001$ & $58.7(4.6)$ & -0.9 & 0.105 \\
\hline ear incline angle, ${ }^{\circ}$ & $17.5(4.6)$ & $11.3(5.3)$ & -6.2 & ${ }^{a}<0.001$ & $12.2(4.4)$ & -5.3 & ${ }^{a}<0.001$ \\
\hline nasal height (n-sn) & $50.6(3.1)$ & $43.3(2.8)$ & -7.3 & ${ }^{a}<0.001$ & $46.0(3.5)$ & -4.6 & ${ }^{a}<0.001$ \\
\hline nasal length (n-pn) & $44.7(3.4)$ & $36.4(3.1)$ & -8.3 & ${ }^{a}<0.001$ & $39.7(3.8)$ & -5.0 & ${ }^{a}<0.001$ \\
\hline tip protrusion (sn-pn) & $19.7(1.6)$ & $18.3(1.3)$ & -1.4 & ${ }^{a}<0.001$ & $19.2(2.1)$ & -0.5 & a 0.029 \\
\hline columella length (c-sn) & $11.5(1.7)$ & $9.7(1.4)$ & -1.8 & ${ }^{a}<0.001$ & $8.9(1.9)$ & -2.6 & ${ }^{a}<0.001$ \\
\hline alar length (ac-pn) & $31.5(1.8)$ & $28.4(2.7)$ & -3.1 & ${ }^{a}<0.001$ & $29.3(3.0)$ & -2.2 & ${ }^{a}<0.001$ \\
\hline alar thickness (al'-al') & $5.3(0.7)$ & $4.8(0.9)$ & -0.5 & ${ }^{\mathrm{a}} 0.045$ & $5.1(0.9)$ & -0.2 & a 0.044 \\
\hline nasal width (al-al) & $31.4(2.0)$ & $35.4(3.3)$ & 4.0 & ${ }^{a}<0.001$ & $35.7(3.3)$ & 4.3 & $\mathrm{a}<0.001$ \\
\hline nasal base width (ac-ac) & $30.5(2.2)$ & $31.6(3.7)$ & 1.1 & 0.259 & $32.0(5.4)$ & 1.5 & ${ }^{\mathrm{a}} 0.015$ \\
\hline mouth width (ch-ch) & $50.2(3.5)$ & $52.9(5.8)$ & 2.7 & a 0.006 & $50.8(5.0)$ & 0.6 & 0.314 \\
\hline upper lip height (sn-st) & $20.1(2.0)$ & $19.4(3.5)$ & -0.7 & 0.442 & $18.4(3.2)$ & -1.7 & ${ }^{a}<0.001$ \\
\hline upper lip thickness (ls-st) & $8.7(1.3)$ & $8.3(1.0)$ & -0.4 & 0.150 & $8.2(1.0)$ & -0.5 & ${ }^{a}<0.001$ \\
\hline lower lip thickness (li-st) & $9.4(1.5)$ & $9.9(1.3)$ & 0.5 & 0.161 & $10.1(1.3)$ & 0.7 & ${ }^{a}<0.001$ \\
\hline nasofrontal angle, & $134.3(7.0)$ & $138.3(7.7)$ & 4.0 & ${ }^{\mathrm{a}} 0.030$ & $138.2(8.1)$ & 3.9 & ${ }^{a}<0.001$ \\
\hline nasofacial angle, ${ }^{\circ}$ & $29.9(3.9)$ & $32.5(5.7)$ & 2.6 & a 0.014 & $31.6(4.2)$ & 1.7 & $\mathrm{a}<0.001$ \\
\hline nasolabial angle, 。 & $104.2(9.8)$ & $101.3(5.5)$ & -2.9 & 0.072 & $96.5(11.3)$ & -7.7 & ${ }^{a}<0.001$ \\
\hline
\end{tabular}

Abbreviations: ac, alar crease point; al, alare; al', alar rim; c, columella point; ch, cheilion; en, endocanthion; ex, exocanthion; g, glabella; gn, gnathion; go, gonion; li, labrale inferioris; ls, labrale superioris; n, nasion; pi, palpebrae inferioris; ps, palpebrae superioris; pn, pronasale; sa, superaurale; sb, subaurale; sn, subnasale; st, stomion; tr, trichion; zy, zygion.

$P$ Values based on unpaired $t$ test with the Welch correction. Unless otherwise noted, data are mean (SD) measurements in millimeters.

a Statistically significant difference.

eyes. An explanation may be that Indian women have a higher eye width/midface width ratio, leading to a greater focus of observers on the eyes. The white sclera produces a striking contrast with the darker Indian skin, again highlighting the eye relative to other facial features. Many plastic procedures strive to change the size or position of an unharmonious feature to divert attention back to the eyes - reduction rhinoplasty, blepharoplasty and browlift are examples.

The majority of women reported the nose as the feature most thought of as unattractive. It is known that rhinoplasty is the most common procedure in ethnic minority groups. ${ }^{16}$ In this study, approximately one-third of women stated they would consider surgery to change a disliked facial feature. Most minority individuals seek to maintain their ethnicity through cosmetic surgeries. ${ }^{4,5,7}$ It can be assumed that IAW would also desire to preserve their ethnic identity. As support for this, it was observed that $24 \%$ of women were wearing nose rings. Nostril piercing is a practice associated with India - these piercings are regarded as a mark of beauty and high social standing. ${ }^{17}$ As seen, many Indian American women living in the United States continue to wear nose rings, a visible and overt display of ethnic identity.

Facial analysis, using anthropometric proportions as a guide, is paramount for planning cosmetic and reconstructive facial surgery. This study is the first to provide an anthropometric and aesthetic analysis of the Indian American woman's face. Several features were correlated with attractiveness: larger and wider-set eyes, a smaller midface, a smaller nose, smaller ears and a larger mouth. In this study, attractive IAW, average IAW and average NAWW all had significant differences for various facial anthropometric measurements.

These results contribute to several concepts of transcultural aesthetics - for a minority ethnic group, facial beauty appears to be an assimilation of deep-rooted ethnic 


\begin{tabular}{|c|c|c|c|}
\hline & Attractive & Average & $P$ Value \\
\hline $\begin{array}{l}\text { Mean Self-Esteem } \\
\text { Score (range: } 1-5 \text { ) }\end{array}$ & 3.7 & 3.4 & ${ }^{\mathrm{a}} 0.039$ \\
\hline $\begin{array}{l}\text { Number (\%) Willing } \\
\text { to Seek Facial }\end{array}$ & $4(25 \%)$ & 29 (34\%) & 0.573 \\
\hline \multicolumn{4}{|l|}{$\begin{array}{l}\text { Plastic Surgery } \\
\text { total: } 33(32 \%)\end{array}$} \\
\hline & & Percentage & \\
\hline \multirow{3}{*}{$\begin{array}{l}\text { Overall Most Liked } \\
\text { Facial Features }\end{array}$} & Eyes & 78 & \\
\hline & Eyebrows & 40 & \\
\hline & Teeth & 25 & \\
\hline \multirow{3}{*}{$\begin{array}{l}\text { Overall Most Disliked } \\
\text { Facial Features }\end{array}$} & Nose & 53 & \\
\hline & Teeth & 21 & \\
\hline & Chin & 15 & \\
\hline
\end{tabular}

features with the prevailing cultural traits and aesthetic standards. The importance of elucidating modern concepts of facial beauty is becoming increasingly understood. Perhaps Ralph Waldo Emerson (known as the first American to champion the wisdom of ancient India) summed it up best when he said, 'If eyes were made for seeing, then beauty is its own excuse for being. 18

\section{Conflict of interest, funding and ethical approval statement}

There are no conflicts of interest to disclose. There are no personal relationships of any author with any organisation. No one has any financial interest in this publication, and there has been no funding for this study. This study was given ethical approval by the Institutional Review Board of the University of California, Irvine.

\section{References}

1. Edler RS. Background considerations to facial aesthetics. J Orthod 2001;28:159-68.
2. Farkas LG, Hreczko TA, Kolar JC, et al. Vertical and horizontal proportions of the face in young adult North American Caucasians: revision of neoclassical canons. Plast Reconstr Surg 1985; 75:328-38.

3. Farkas LG, Katic MJ, Forrest CR. International anthropometric study of facial morphology in various ethnic groups/races. J Craniofac Surg 2005;16:615-46.

4. Porter JP, Olson KL. Anthropometric facial analysis of the African American woman. Arch Facial Plast Surg 2001;3:191-7.

5. Milgrim LM, Lawson W, Cohen AF. Anthropometric analysis of the female Latino nose. Revised aesthetic concepts and their surgical implications. Arch Otolaryngol Head Neck Surg 1996; 122:1979-86.

6. Dawei W, Guozheng Q, Mingli Z, et al. Differences in horizontal, neoclassical facial canons in Chinese (Han) and NorthAmerican Caucasian populations. Aesth Plast Surg 1997;21: 265-9.

7. Choe KS, Sclafani AS, Litner JA, et al. The Korean-American woman's face: anthropometric measurements and quantitative analysis of facial aesthetics. Arch Facial Plast Surg 2004;6: 244-52.

8. U.S. Census Bureau. Avaliable at: http://www.census.gov; 1995.

9. Bernstein IH, Lin TD, McClellan P. Cross- vs within-racial judgments of attractiveness. Percept Psychophys 1982;32: 495-503.

10. Grammer K, Thornhill R. Human (Homo sapiens) facial attractiveness and sexual selection: the role of symmetry and averageness. J Comp Psychol 1994;108:233-42.

11. Powell N, Humphries B. Proportions of the aesthetic face. New York, NY: Thieme-Stratton Inc; 1984.

12. Cunningham MR. Measuring the physical in physical attractiveness: quasi-experiments on the sociobiology of female facial beauty. J Pers Soc Psychol 1986;50:925-35.

13. Langlois JH, Roggman LA, Casey RJ, et al. Infant preferences for attractive faces: rudiments of a stereotype? Dev Psychol 1987;23:363-9.

14. Darwin C. The expression of the emotions in man and animals. London, UK: Harper Collins; 1872. 1998:176-:194.

15. Strzalko J, Kaszycka KA. Physical attractiveness: interpersonal and intrapersonal variability of assessments. Soc Biol. 1991;39: $170-6$.

16. Cooper LP. Dramatic rise in ethnic plastic surgery in 2005. Avaliable at:. Medical News Today http://www.medical newstoday.com/articles/39814.php; 18 Mar 2006.

17. Niptoon. Nostril piercing. Avaliable at: WordPress.com http:// nicebodypiercing.wordpress.com; 24 Apr 2008.

18. Emerson RW. The Rhodora. In: Lounsbury TR, editor. Yale Book of American Verse. New Haven, CT: Yale University Press; 1847. 1999. 